\title{
CHRONIC SUPPURATIVE OTITIS MEDIA- AETIOLOGY AND THEIR ANTIBIOGRAM
}

\author{
Ramya Sablur Narayana1, Malini Jagannatha Rao ${ }^{2}$
}

${ }^{1}$ Assistant Professor, Department of Otolaryngology, ESIC-MC-PGIMSR, Bengaluru, Karnataka.

2Assistant Professor, Department of Microbiology, ESIC-MC-PGIMSR, Bengaluru, Karnataka.

\section{BACKGROUND}

ABSTRACT

Chronic Suppurative Otitis Media (CSOM) is a common infectious chronic ear disease in India. The present study of Department of ENT OPD of ESIC-MC-PGIMSR, Bangalore, was aimed to identify aerobic bacterial isolates associated with CSOM and their antibiogram in patients.

\section{MATERIALS AND METHODS}

Prospectively studied one hundred and thirteen patients with CSOM with ear swabs taken and cultured for bacteria. The standard method of isolation and identification was followed. Antimicrobial susceptibility of the bacterial isolates was performed by KirbyBauer's disc diffusion method.

\section{RESULTS}

Pseudomonas aeruginosa 28 (49.1\%) was the most predominant organism followed by Staphylococcus aureus 16 (28\%). Fungi accounted for $3(2.6 \%)$ of the isolates. The antimicrobial profile of the major isolates showed $75 \%$ of Pseudomonas aeruginosa and $62.5 \%$ of Staphylococcus aureus sensitive to ciprofloxacin.

\section{CONCLUSION}

Pseudomonas aeruginosa is the most common isolate followed by Staphylococcus aureus. The study of microbial pattern and their antibiotic sensitivity determines the prevalent bacterial organisms causing CSOM in local area and to start empirical and more targeted treatment of otitis media and its complications for successful outcome, thus to prevent the emergence of resistant strains.

\section{KEYWORDS}

Chronic Suppurative Otitis Media, Aerobic Bacterial Isolates, Pseudomonas Aeruginosa, Staphylococcus Aureus, Bacterial Resistance.

HOW TO CITE THIS ARTICLE: Narayana RS, Rao MJ. Chronic suppurative otitis media- aetiology and their antibiogram. J. Evolution Med. Dent. Sci. 2018;7(12):1480-1483, DOI: 10.14260/jemds/2018/335

\section{BACKGROUND}

Infections of the middle ear space and their sequelae have plagued mankind from the beginning of time. First described by Hippocrates in $450 \mathrm{BC}$, this universally observed process continues to present one of the most perplexing medical problems of infancy and childhood, while being the cause of hearing loss in paediatric age group. ${ }^{1}$

Chronic suppurative otitis media (CSOM) is defined as chronic inflammation of middle ear and mastoid cavity, which presents with recurrent ear discharge or otorrhoea through a tympanic perforation. The episode of otorrhoea is provoked by upper respiratory tract infections. This is particularly common in children. ${ }^{2}$ CSOM is a destructive disease with irreversible sequel and can proceed to serious intra- and/or extracranial complications. ${ }^{3}$ CSOM is usually classified into two types- tubotympanic and attico-antral depending on whether the disease process affects the pars tensa or pars flaccida of the tympanic membrane. ${ }^{4}$ Tubotympanic is called as a safe type or benign type, because much complication is not noted.5 Whereas life-threatening complications are associated with unsafe or dangerous attico-antral type.

'Financial or Other Competing Interest': None.

Submission 06-02-2018, Peer Review 07-03-2018,

Acceptance 12-03-2018, Published 19-03-2018.

Corresponding Author:

Malini Jagannatha Rao,

Department of Microbiology, ESIC-MC-PGIMSR,

Rajajinagar, Bengaluru-560010, Karnataka.

E-mail: malinirao74@gmail.com

DOI: $10.14260 /$ jemds $/ 2018 / 335$
Various complications like mastoid abscess, deafness, lateral sinus thrombosis, paralysis, meningitis and intracranial abscess can occur when there is spread of infection to adjacent structures from middle ear.6,7 In almost $50 \%$ of the cases, there can be complications like hearing loss if there is chronic ear discharge. ${ }^{8}$ In childhood, acute otitis media if improperly treated or improperly managed can lead to CSOM, which can be seen in adulthood with chronic ear discharge, maybe up to several years. ${ }^{9-12}$ The incidence of chronic suppurative otitis media is higher in developing countries especially among low socio-economic society because of malnutrition, overcrowding, poor hygiene, inadequate health care and recurrent upper respiratory tract infection. ${ }^{13}$

CSOM for development may be responsible of wide range of organisms. The increasing emergence of bacterial strains which are resistant to known antimicrobial agents is a significant cause of treatment failure. CSOM has received considerable attention, not only because of its high incidence and chronicity but also because of issues such as bacterial resistance and ototoxicity with both topical and systemic antibiotics. ${ }^{14}$ The indiscriminate, haphazard and hay-hearted use of antibiotics and the poor follow-up of the patients have resulted in the persistence of low-grade infections. ${ }^{15}$ Knowledge of the common causative organisms and their antibiotic sensitivity is helpful in deciding the drug of choice in perioperative management of unsafe CSOM. ${ }^{16}$ In-vitro antibiotic sensitivity pattern is very important for the clinician to plan a general outline of treatment for a patient 
and can minimise complications that may require surgery for a chronically discharging ear. ${ }^{4}$

Therefore, the microbial culture and sensitivity will help in appropriate management of otitis media and its complications, and thus preventing the emergence of resistant bacterial strains.

This study was performed to determine the aerobic bacterial flora and their antibiotic susceptibility pattern in cases of CSOM who attended the ENT Department OPD with complaints of chronically discharging ear.

\section{MATERIALS AND METHODS}

This prospective descriptive study was conducted for a period from Aug 2013 to Feb 2014 at ESIC-MC-PGIMSR, Rajajinagar, Bangalore, a tertiary care hospital. One hundred and thirteen patients, who presented to the ENT department with a history of chronic discharging ear were studied.

The study was approved by our Institutional Ethical Committee and the written informed consent (signed by patient or parent/ guardian) was obtained at enrolment. A total of 113 patients clinically diagnosed with CSOM were included in the study.

\section{Inclusion Criteria}

1. Patients who attended the outpatient clinics with ear discharge for more than 6 - 12 weeks.

2. Topical/ systemic antibiotics were stopped or not received for 14 days before the study.

\section{Exclusion Criteria}

1. Immunocompromised patients, patients on dialysis, receiving immunosuppressive drugs, diabetic, tuberculosis.

2. Children and adults with cleft lip/ cleft palate deformation.

\section{Statistical Analysis}

Since this is a descriptive study, the results were analysed as percentage.

After obtaining consent from the patient, the ENT surgeon collected the sample by pulling the pinna of the ear outward, laterally and backwards after which the sterile swab stick was gently introduced into the external auditory meatus and then gently rotated and the pus specimen was collected.

Two pus samples were collected from the middle ear and the samples were immediately sent to the Microbiology Laboratory for bacterial studies. In the laboratory first swab was used for Gram staining, acid fast staining and $\mathrm{KOH}$ mount. The ear discharges were examined microscopically (in $10 \%$ potassium hydroxide) for the presence of epithelial cells, pus cells, budding yeast cells, fungal hyphae and spores, etc. The second swab was inoculated on blood agar, MacConkey's agar and chocolate agar media and was incubated at $37^{\circ} \mathrm{C}$ for $24 \mathrm{hrs}$. The organisms were identified by using standard procedure. The antimicrobial susceptibility of the aerobic bacterial isolates was performed by KirbyBauer's disc diffusion method. ${ }^{17,18}$

\section{RESULTS}

The study included 113 patients in the age ranged from 6 months to 70 years with $42(37.1 \%)$ cases seen in peak age group of 31 - 40 years followed by $25(22.1 \%)$ cases in age group of 21 - 30 years. The male and female distribution was $66(58.4 \%)$ and $47(41.6 \%)$ respectively, (Table 1$)$.

Out of total 113 ear swabs processed monomicrobial growth was seen in 57 (50.4\%), whereas 8 (7.1\%) samples showed polymicrobial growth, $26(23.1 \%)$ samples showed no growth, $19(16.8 \%)$ showed the growth of skin commensal and 3 (2.6\%) showed fungal growth (Table 2).

Pseudomonas aeruginosa 28 (49.1\%) was the most predominant organism followed by Staphylococcus aureus 16 (28\%), Acinetobacter spp. 4 (7\%), Citrobacter spp. 3 (5.3\%) and Klebsiella pneumoniae and Proteus mirabilis 2 (3.5\%) each and Enterobacter cloacae and Streptococcus spp. 1 (1.7\%) each, (Table 3).

The antibiotic susceptibility pattern of the 28 isolates of pseudomonas shows $100 \%$ susceptibility to imipenem followed by piperacillin-tazobactam (92.8\%), amikacin (64.3\%), ciprofloxacin (75\%), co-trimoxazole showed highest resistance (85.7\%) followed by Amoxyclav (67.9\%), (Figure 1).

Drug susceptibility pattern for Staphylococcus aureus showed $100 \%$ susceptibility to vancomycin and tetracycline followed by $87.5 \%$ susceptibility to gentamicin and amikacin, $81.3 \%$ of isolates were susceptible to erythromycin and $62.5 \%$ susceptibility to ciprofloxacin (Figure 2). Among the Staphylococcus aureus, 3 (17.6) were Methicillin-resistant Staphylococcus aureus (MRSA).

\begin{tabular}{|c|c|c|c|}
\hline Age in Years & Male & Female & Total (\%) \\
\hline $0-10$ & 6 & 2 & $8(7.1)$ \\
\hline $11-20$ & 10 & 3 & $13(11.6)$ \\
\hline $21-30$ & 13 & 12 & $25(22.1)$ \\
\hline $31-40$ & 22 & 20 & $42(37.1)$ \\
\hline $41-50$ & 9 & 5 & $14(12.4)$ \\
\hline $51-60$ & 4 & 4 & $8(7.1)$ \\
\hline $61-70$ & 2 & 1 & $3(2.6)$ \\
\hline \multicolumn{4}{|c|}{ Total } \\
\hline \multicolumn{4}{|c|}{ Table 1. Age and Sex-Wise Distribution of Samples } \\
\hline
\end{tabular}

\begin{tabular}{|c|c|c|}
\hline Sl. No. & Type of Isolate & No. (\%) \\
\hline 1 & Pure Bacterial Isolate & $57(50.4)$ \\
\hline 2 & Mixed Culture & $08(7.1)$ \\
\hline 3 & No Growth & $26(23)$ \\
\hline 4 & Commensal & $19(16.8)$ \\
\hline 5 & Fungal & $03(2.6)$ \\
\hline 6 & Total & $\mathbf{1 1 3 ( 1 0 0 )}$ \\
\hline \multicolumn{3}{|c|}{ Table 2. Type of Isolate } \\
\hline
\end{tabular}

\begin{tabular}{|c|c|c|}
\hline Sl. No. & Microorganism & No. (\%) n=57 \\
\hline 1 & $\begin{array}{c}\text { Pseudomonas } \\
\text { aeruginosa }\end{array}$ & $24(49.1)$ \\
\hline 2 & Staphylococcus aureus & $16(28)$ \\
\hline 3 & Acinetobacter spp. & $4(7)$ \\
\hline 4 & Citrobacter spp. & $3(5.3)$ \\
\hline 5 & Klebsiella spp. & $2(3.5)$ \\
\hline 6 & Proteus mirabilis & $1(1.7)$ \\
\hline 7 & Enterobacter spp. & $1(1.7)$ \\
\hline 8 & Streptococcus spp. & 57 \\
\hline \multicolumn{2}{|c|}{ Table 3. Organisms Isolated from Pure Culture } \\
\hline
\end{tabular}




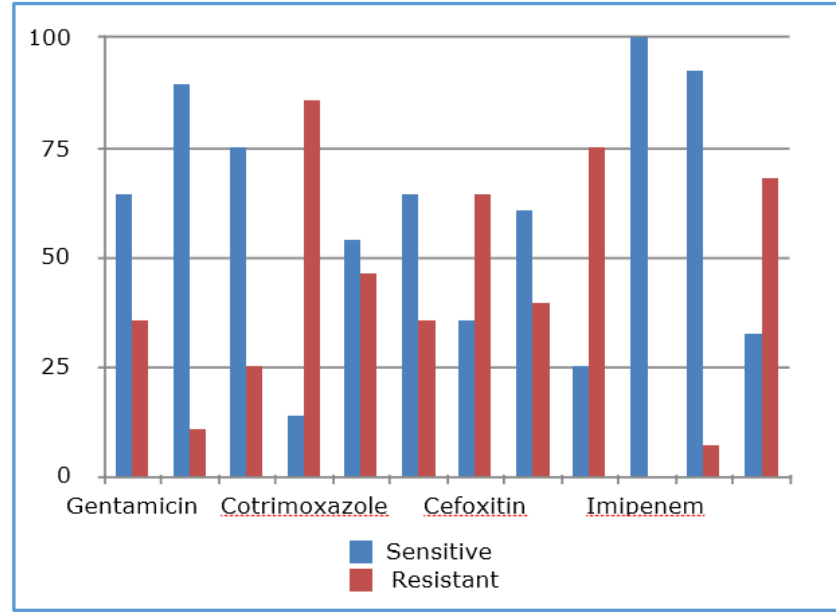

Figure 1. Antibiotic Susceptibility (\%) of Pseudomonas aeruginosa

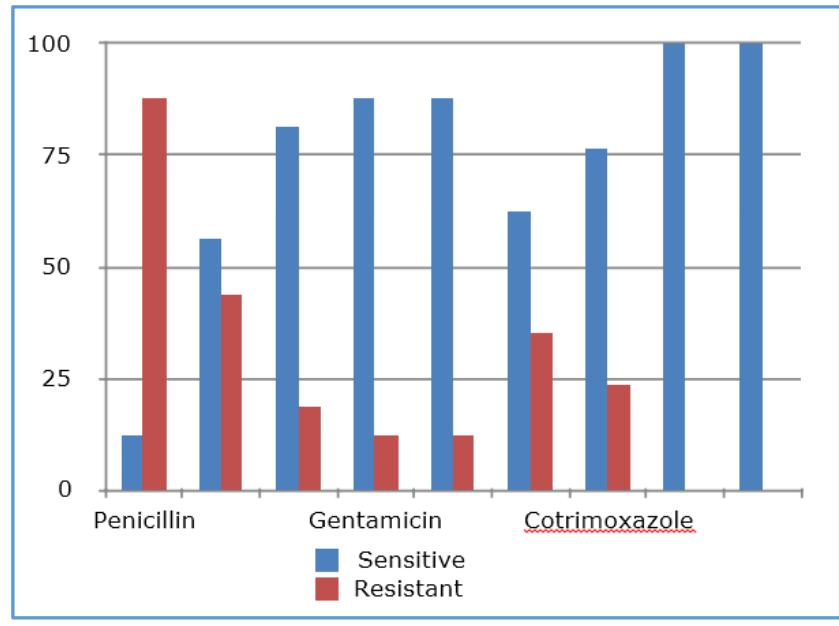

Figure 2. Antibiotic Susceptibility (\%) of Staphylococcus aureus

\section{DISCUSSION}

India is one of the countries with high prevalence of CSOM. ${ }^{19}$ Our study revealed monomicrobial growth in $50.4 \%$ of samples. Polymicrobial growth is seen in $7.1 \%$ of samples, this may be attributed to improper collection of ear swab. $23 \%$ of samples were sterile, probably because of prior antibiotic therapy which the patient might not have revealed during the history taking. Coagulase negative Staphylococcus (CONS) grew in $16.8 \%$ of samples. CONS is usually considered as commensal organism of the skin, but rarely can become an opportunistic pathogen. Fungal infections of the middle ear are common as fungi thrive well in moist pus. The most commonly found fungi in CSOM are Candida species and Aspergillus species. ${ }^{20}$ In the present study fungal aetiology was found in $3(2.6 \%)$ cases, out of which 2 were Candida albicans and one isolate was Aspergillus niger (Table 2).

Studies of microbiology of chronic discharging ears have revealed that the most frequently isolated bacteria were Pseudomonas aeruginosa (31.1\%), Staphylococcus aureus (19.1\%), Proteus mirabilis (7.7\%), Klebsiella spp. (1\%) and fungi. Review of literature of bacterial flora in CSOM in different states of India showed P. aeruginosa as the main isolate.21 Our study also revealed that Pseudomonas aeruginosa (49.1\%) was the most common isolate in CSOM followed by Staphylococcus aureus (28\%). Anaerobic culture was not carried out.

The increased rate of isolation of Pseudomonas aeruginosa has its own implications, as this organism is an important cause of nosocomial infections and has developed resistance to even many potent antibiotics. Pseudomonas infections are mostly seen where there is discontinuity of normal skin or when normal flora is replaced by it due to constant use of topical antibiotics. The easy availability of the over-the-counter topical antibiotic drops and their rampant use breeds an environment where organisms like Pseudomonas aeruginosa can grow and cause serious intra and extracranial complications. ${ }^{22}$

Antimicrobial susceptibility of Pseudomonas aeruginosa in our study revealed that $100 \%$ isolates were susceptible to Imipenem, 92.8\% isolates were susceptible to Piperacillintazobactam, $89.3 \%$ susceptible to Amikacin and $75 \%$ susceptibility to Ciprofloxacin.

Globally, a change has been noticed in the susceptibility of Pseudomonas aeruginosa towards Quinolones in the last few decades. One study carried out in 1996 in Turkey revealed only $6 \%$ of Pseudomonas aeruginosa isolates to be resistant to Ciprofloxacin, ${ }^{23}$ whereas in South Korea in a study carried out in 2004 ciprofloxacin resistance was noted in $100 \%$ of the isolates. ${ }^{24}$ In the Indian scenario, 30\% resistance in Uttarakhand study ${ }^{13}$ and $62.5 \%$ resistance in Raghavendra Singh Gaur et $\mathrm{al}^{25}$ was noted. In contrast, our study has shown $75 \%$ of isolates still susceptible to Ciprofloxacin. With these type of results in the present era, the otorhinolaryngologist has to depend on Ciprofloxacin oral preparations to treat Pseudomonas aeruginosa, though the organism is retaining its susceptibility to higher antibiotics that are available in injectable form and can be prescribed in complicated forms of Pseudomonas aeruginosa infection.

While for Staphylococcus aureus, $81.3 \%$ of the isolates were susceptible to erythromycin and only $62.5 \%$ were susceptible to ciprofloxacin.

Therefore, evaluation of microbiological pattern in local area becomes helpful in prescribing empirical antibiotics for successful treatment of otitis media and thus minimising its complications and emergence of resistant strains.

\section{CONCLUSION}

Pseudomonas aeruginosa and Staphylococcus aureus were found to be the most common cause of CSOM in our study. $75 \%$ of Pseudomonas aeruginosa and $62.5 \%$ of Staphylococcus aureus were susceptible to the routinely used drug ciprofloxacin. Also, the resistance pattern of the microorganisms usually keeps changing. So it is desirable for laboratory to culture all cases of CSOM for bacteria and fungus on a routine basis. Hence, routine use of topical antibiotics for any case of CSOM as empirical therapy must be reviewed and judicial use of antibiotics is recommended. Appropriate antimicrobial drugs should be prescribed after proper diagnosis of the causative organism and its antimicrobial susceptibility pattern. The patients should also be advised to take the drugs for the complete prescribed duration without stopping in the middle. This will not only help in minimising the complications, but also help in preventing the emergence of resistant strains. 


\section{REFERENCES}

[1] Healy GB. Otitis media and middle effusions. Otorhinolaryngology. Head and neck surgery. John Jacob Ballenger. 15th edn. Williams and Wilkins, 1996:1003-9.

[2] WHO library cataloguing-in-publication data. Chronic suppurative otitis media. Burden of illness and management options: WHO 2004.

[3] Poorey VK, Lyer A. Study of bacterial flora in csom and its clinical significance. Indian J Otolaryngol Head Neck Surg 2002;54(2):91-5.

[4] Kumar H, Seth S. Bacterial and fungal study of 100 cases of chronic suppurative otitis media. J Clin Diagn Res 2011;5:1224-7.

[5] Rout MR, Mohanty D, Vijaylaxmi Y, et al. Prevalence of cholesteatoma in chronic suppurative otitis media with central perforation. Indian J Otol 2012;18(1):710.

[6] Berman S. Otitis media in developing countries. Pediatrics 1995;96(1 Pt 1):126-31.

[7] Wiwanitkit $S$, Wiwanitkit V. Pyogenic brain abscess in Thailand. N Am J Med Sci 2012;4(6):245-8.

[8] Morris PS, Leach AJ. Prevention and management of chronic suppurative otitis media in aboriginal children: a practical approach. Comm Ear Hearing $\mathrm{H}$ 2007;4:22-5.

[9] Elemraid MA, Brabin BJ, Fraser WD, et al. Characteristics of hearing impairment in Yemeni children with chronic suppurative otitis media: a casecontrol study. Int J Pediatr Otorhinolaryngol 2010;74(3):283-6.

[10] Ologe FE, Nwawolo CC. Chronic suppurative otitis media in school pupils in Nigeria. East Afr Med J 2003;80(3):130-4.

[11] Bluestone CD. Epidemiology and pathogenesis of chronic suppurative otitis media: implications for prevention and treatment. Int J Pediatr Otorhinolaryngol 1998;42(3):207-23.

[12] Kenna MA. Epidemiology and natural history of chronic suppurative otitis media. Ann Otol Rhinol Laryngol 1988;97(2):8.

[13] Prakash R, Juyal D, Negi V, et al. Microbiology of chronic suppurative otitis media in a tertiary care setup of Uttarakhand State, India. N Am J Med Sci 2013;5(4):282-7.

[14] Nikakhlagh S, Khosravi AD, Fazlipour A, et al. Microbiologic findings in patients with chronic suppurative otitis media. J Med Sci 2008;8(5):503-6.
[15] Malkappa SK, Kondapaneni S, Surpam RB, et al. Study of aerobic bacterial isolates and their antibiotic susceptibility pattern in chronic suppurative otitis media. Indian Journal of Otology 2012;18(3):136-9.

[16] Kumar S, Sharma R, Saxena A, et al. Bacterial flora of infected unsafe CSOM. Indian Journal of Otology 2012;18(4):208-11.

[17] Forbes BA, Sahm DF, Weissfeld AS. Bailey and Scott's diagnostic microbiology. $10^{\text {th }}$ edn. St. Louis, Misssouri, USA: Mosby Inc, 1998.

[18] Clinical and Laboratory Standard Institute. Performance Standards for Antimicrobial Susceptibility Testing. USA: Pennsylvania, 2007;1(1):M2-A9.

[19] Acuin J. Global burden of disease due to chronic suppurative otitis media: disease, deafness, deaths and DALYs chronic suppurative otitis media-burden of illness and management options. Geneva: World Health Orgnization 2004;9-23. http:// www.who.int/pbd/deafness/activities/hearing_c are/otitis_media.pdf.

[20] Ibekwe AO, al Shareef Z, Benayam A. Anaerobes and fungi in chronic suppurative otitis media. Ann Otol Rhinol Laryngol 1997;106(8):649-52.

[21] Ricciardiello F, Cavaliere M, Mesolella M, et al. Notes on the microbiology of cholesteatoma: clinical findings and treatment. Acta Otorhinolaryngol Ital 2009;29(4):197-202.

[22] Jayanthi RS, Venkatesh R, Jeya M. Study of aerobic bacterial and fungal etiology of chronic suppurative otitis media in tertiary care hospital in out skirts of Chennai, India. International Journal of Research in Health Sciences 2013;1(3):199-203.

[23] Altuntas A, Aslan A, Eren N, et al. Susceptibility of microorganisms isolated from chronic suppurative otitis media to ciprofloxacin. Eur Arch Otorhinolaryngol 1996;253(6):364-6.

[24] Jang CH, Park SY. Emergence of ciprofloxacin resistant pseudomonas in chronic suppurative otitis media. Clin Otolaryngol Allied Sci 2004;29(4):321-3.

[25] Gaur RS, Mathew J, Varghese AM, et al. Microbiological pattern of ear swabs in chronically discharging ears in a tertiary care hospital in India. Indian Journal of Otology 2013;19(2):51-4. 